\title{
The Application of Multicultural Music in College Music Education
}

\author{
Huawei Zhang \\ Department of Music, Dongchang College of Liaocheng University, Shandong, China, 252000
}

Keywords: Multicultural; Music Education; Ethnic Differences.

Abstract: At present, diversified music education has become a key research topic in music education. Using diversified music to carry out music teaching in colleges and universities can overcome the traditional cultural parochialism and promote the development of music teaching. Based on the analysis of multicultural music education in foreign countries, this paper explores the important role of applying multicultural music education in music education in China's colleges and universities in the development of music in China.

\section{Introduction}

Different countries have great differences in ethnic, linguistic and religious beliefs, and the cultures formed on this basis are pluralistic. In music teaching in Colleges and universities, if we want to better carry out teaching, we must understand these multicultures and respect different cultures. Every country is confronted with a cultural contradiction, that is, on the basis of a unified culture, it can fully display the characteristics of different nationalities and ethnic groups, so that multiculturalism can be put forward. At the same time, the proposal of multi-culture fully reflects the respect and attention of all nations, and greatly enriches the cultural connotation of the country through the integration of the cultures of all nationalities. Multicultural music is developed on the basis of multiculturalism. The specific content of multicultural music is shown in Figure 1 below.

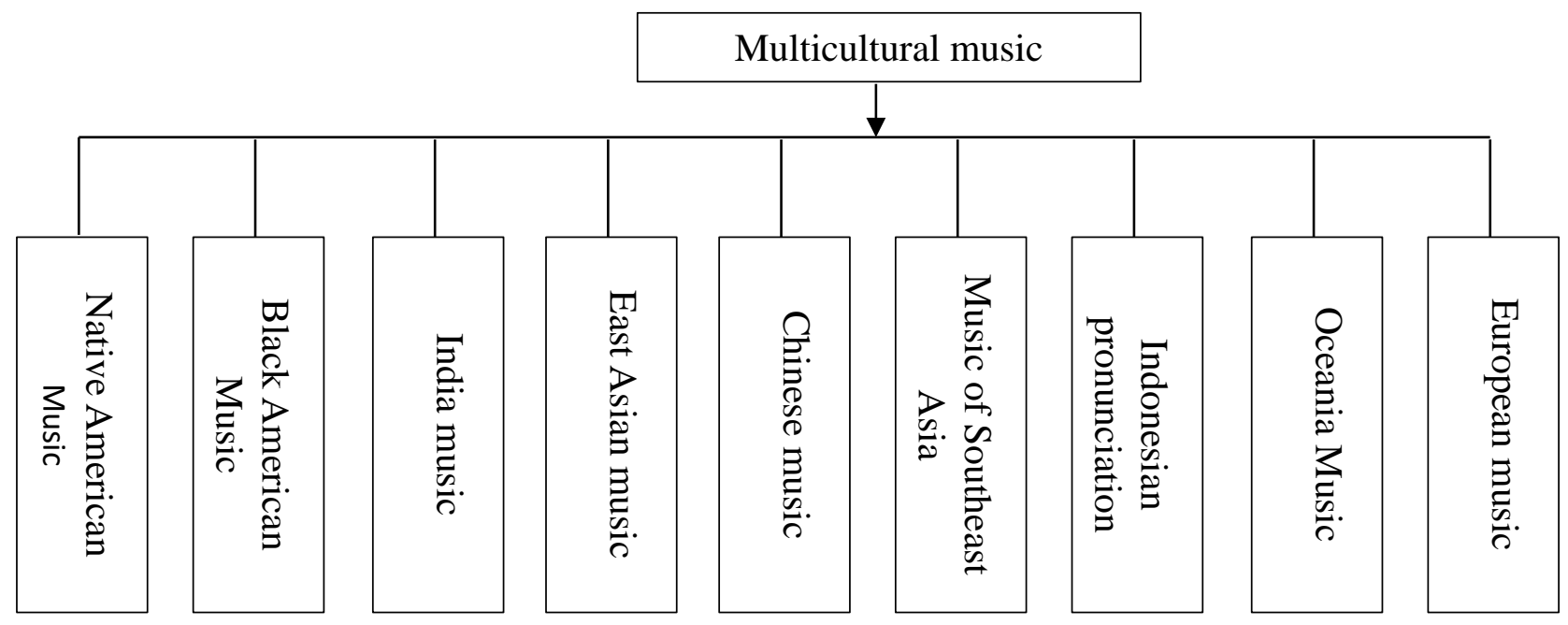

Figure 1 The Specific Contents of Multicultural Music 


\section{Multicultural Education and Multicultural Music Education}

\subsection{Multicultural Education}

Multiculturalism refers to the differences in historical background, culture and religious beliefs between different countries. Based on these differences, multiculturalism emerges. Ethnic beliefs, cultures and languages are unique to ethnic groups in the course of their development. In order to change the situation of fragmentation and achieve national unity as soon as possible, these ethnic groups will gather all forces to strive for national unity and embody the cultural characteristics of each ethnic group in the unity. Thus, the emergence and development of multiculturalism is the foundation and strength of national unity. Under the development of this culture, the characteristics of different nationalities are embodied, which enables different nationalities to respect and learn from each other. Multicultural education is the main way to implement multicultural education. By comparing different cultures of different nationalities, the educated can be more easily accepted and their own cultural knowledge can be increased. This cultural background is very helpful for learning and work ${ }^{[1]}$.

\subsection{Analysis of Multicultural Music Education}

There is a close relationship between multicultural education and multicultural music education. They have similarities. Different countries produce different musical styles based on different cultures, which all show their national characteristics. Each country has its own culture and music, and each country's music can highlight the characteristics of different nationalities. Therefore, each country's understanding of music should not be limited to its own country, but should focus on the whole world. It also promotes the development of diversified music education. American colleges and universities have higher requirements for music education in universities. Music undergraduates must complete the course of world music before they can be allowed to graduate ${ }^{[2]}$.

Music teacher qualification. And this is the government's mandatory regulation on music education. The United States itself has more than 270 nationalities and ethnic groups, and the cultures of each ethnic group have their own characteristics. Therefore, the United States has its own complexity in music learning, while the United States has to learn the world music, which fully reflects the profound understanding of multicultural music education in the United States. It is the basic educational concept of the harmonious coexistence mode of all nationalities and ethnic groups to reflect the multicultural music education in the United States to all nationalities in the world.

\section{The Problems of Diversified Music Education in Colleges and Universities in China}

\subsection{Non-standard management}

The continuous development of society and the advancement of quality education reform have put forward higher requirements for all aspects of teachers'quality. And teachers'teaching ability directly determines their salary and Title evaluation. As a result, many teachers pay more and more attention to the title evaluation, thus neglecting the cultivation of music teaching ability and lacking knowledge and learning of music teaching ${ }^{[3]}$. As a result, teachers only mechanically impart music knowledge to students in the teaching process, ignoring the exchange of national culture, so that teaching management can not be scientific and reasonable. 


\subsection{Inadequate participation in the educational process}

The basic way of music teaching is that teachers impart music knowledge to students in class. A positive and active classroom atmosphere is the guarantee of improving teaching effect and arousing learning enthusiasm. Therefore, in teaching, teachers always focus on textbook narration, ignoring the cultivation of self-exploration ability, leading students into a learning misunderstanding. And music teaching lays stress on knowledge and basic skills training, ignoring students'feelings and practical experience of music. By adopting the single and old teaching methods in the past, students can only imitate learning blindly, and it is difficult to develop their interest and potential in music. This kind of education seriously restricts students'innovative ability and imagination, which leads to the restriction of students' thinking and makes it difficult to achieve greater success in the development of music. At present, the content of music textbooks in Colleges and universities is not perfect, which can not reflect the characteristics of diversified music. Moreover, most music teachers are good at theoretical research and explanation, which makes it difficult for students to have practical opportunities ${ }^{[4]}$. This kind of teaching method can only make students understand music knowledge initially and lack practical ability. Students usually only have the opportunity to participate in the practice before graduation. Therefore, college graduates are extremely deficient in integrating theory with practice, resulting in incompetence in future teaching practice.

\section{Measures to Strengthen the Application of Multicultural Music in College Music Teaching}

Nowadays, diversified music has become a new trend of music teaching in accordance with the development of the times. Under the background of cultural revitalization and efforts to restore national culture, diversified music has begun to attract the attention of music teaching in Colleges and universities. The concept of diversification has been established, more diversified music courses have been set up, and the focus on local music culture has become the center of music teaching.

\subsection{Establishing Multicultural Idea in College Music}

According to the analysis of pluralistic music from the global music view, the world music is a flowing note. Although the structure of each note is basically the same, different musical styles are determined by different notes, and different musical styles constitute a unique national movement, which can be practiced in music performance and creation. This flowing music has been expanding in a wide range of fields in the world music circle and continuously contracting in a narrow range ${ }^{[5]}$. And the world music will not stop flowing in a certain historical or geographical scope, but throughout the whole world, we must stand at the height of the world to understand and appreciate it. After recognizing the multi-culture, the way of music learning is more diversified and the train of thought is broader. It is not confined to a fixed range, but evolves into a kind of social demand. The cross-cultural and cross-regional characteristics of multicultural music have been recognized by people. It is of great significance for future music creation to achieve even expansion through this understanding and play a role in the international community. In view of the differences in beliefs, cultures and regions of various countries in the world, more and more different cultural styles have begun to emerge, and the world music presents different characteristics. Therefore, under the multi-cultural music education, it is necessary to constantly change the concept of education, especially to change the concept of music dominated by the West into that of national music, so as to fully learn from and absorb different national sounds. It is the right way to improve and reform the advantages of music teaching and to create a music teaching method that is in line with our own 
nation.

\subsection{Strengthen the Setting of Diversified Music Courses in College Music Education}

Integrating diversified music forms into music teaching in Colleges and universities can not only introduce music from different countries and feel the cultural diversity of different countries, but also think from the perspective of globalization development, so that music teaching can adapt to the development trend of globalization is the most important. Diversified music education is a course offered by colleges and universities. It is not simply to integrate music forms from different countries. This simple way of integration is undoubtedly a tremendous pressure for students who do not have a diversified understanding, and it is very easy to make students fear the production of music. As a result, colleges and universities need to screen the music forms of different countries while introducing them, retain the good ones and remove the bad ones, so as to embody the value of diversified music teaching. Taking the cultural forms and views of different nationalities as a link, we should take students as the main body of teaching, rectify the inherent music mode, improve students'cognitive ability and discrimination ability of music, enhance all aspects of music skills, and cultivate good music feelings. Music culture of all nationalities in the world is rich and varied, and students can not fully understand it in College education. Therefore, when constructing a diversified music curriculum, universities must choose the music they absorb. According to the basic music ability of students, regional characteristics and the hardware conditions of schools, they should choose some classical music works and music teaching phases of all nationalities in the world. Fusion, broaden students'musical horizons, so that they realize more cultural music. Setting up diversified music in Colleges and universities can not only promote the development of local music, but also enrich students'music knowledge and deepen their comprehensive understanding of music.

\section{Conclusion}

To sum up, various music forms have emerged in different music backgrounds all over the world. Diversity has deeper connotation and rich and diverse music system in its continuous development. If we can recognize and respect this difference in culture and music form in music teaching in colleges and universities, we can absorb and draw lessons from it, learn more about diversified music, and enhance our sense of world recognition. Although there are still many problems in the diversified music education in colleges and universities in China, such as non-standard teaching management, insufficient participation of students in teaching activities, lack of identity with the music forms of our nation and other countries in the world, inability to actively participate in music learning and music education in the form. These problems are often encountered in music teaching, but as long as teachers and students work together, constantly absorb different national music, learn the connotation and essence of these diversified music, as long as the music education in Colleges and universities does not divorce from the local culture, integration and creation of different national cultures can expand students'music path and adapt to the development trend of the times.

\section{References}

[1] Yanyu. Integration of Multicultural Music Education into Music Teaching in Colleges and Universities [J]. Think tank era, 2018 (40): $152+154$.

[2] Zhang Kedong. Practice of Multicultural Music Education in College Music Education [J]. Shaanxi Education (Higher Education), 2018 (06): 25-26.

[3] Li Guyue. Application of Multicultural Music Education in College Music Education [J]. Heilongjiang Science, 2017,8(22): 100-101. 
[4] Lan Xiaomei. National Music Inheritance and Development in College Music Education under the Multicultural Background [J]. Journal of Tonghua Normal University, 2015, 36 (12): 113-115.

[5] Li Jian. Research on Multicultural Music Education in Hebei University of Science and Engineering [D]. Hebei Normal University, 2012. 